\title{
Paradoxical Support for the So-Called "Osteological Paradox": An Attempt to Extirpate Evidence-Based Challenges to Speculation-Based Paradigms?
}

\author{
Bruce Rothschild* \\ Carnegie Museum of Natural History, USA
}

\begin{abstract}
The "osteological paradox" has seemingly been utilized as a mechanism to permit promulgation of speculations, compromising their testing and falsification. Such repetition of consensus-based opinions has achieved the status of almost religiously-observed mythologies. The "osteological paradox" would seem to offer an argument to denigrate evidence-based studies - if that speculation, and it is only unsubstantiated speculation, actually had evidential support. It does not. Attempts to provide support have been compromised by use of faulty comparative or strawman samples and lack of understanding of the spectrum of disease manifestations as an epidemiological phenomenon. Examined critically the "osteological paradox" was found to bear no clothes.
\end{abstract}

Keywords

Osteological paradox, Speculation, Evidence-based, Bias

\section{Introduction}

Wood, et al. [1] and Ortner [2] challenged accurate reflection of health/representativeness by cemetery burials, as to the population from which they were drawn and as to the prevalence of diseases, suggesting their perspective of increase (in disease) might represent greater life expectancy. McFadden and Oxenham [3] utilize this speculation to suggest that their findings could suggest either representing fraility (unhealthy) or resilience (surviving ill health, so bone shows disease). Wright and Yoder [4] used the speculation of Wood, et al. [1] to state "age distribution of skeletons in a cemetery reveals more about fertility levels than it does about mortality patterns." They then offered the further speculation (without evidence) that "the abundance of lesions of a particular condition seen in a cemetery sample does not directly reflect its abundance in the living population at any given point in time." There seems to have been a failure to recognize that speculation (the scientific term is hypothesis formation) is the starting point for science, something to be tested and from which other hypotheses can be generated. McFadden and Oxenham [3] noted more than 1400 Google Scholar citations discussing the osteological paradox, but no resolution as to its validity and without increasing our understanding of the issues they investigated.

So, is there actually any evidence that such a paradox exists? Persistence of this speculation seems to result from inappropriate comparisons [e.g., younger individuals killed in combat versus the multigenerational general population from which the comparison sample was drawn were drawn [5]. They were not comparable groups, so it is no surprise that they appeared different. That comparison did not support the existence of an osteological paradox. There have been other recent (compared to the original speculation) attempts to support the speculation (e.g., [4,6-10]), sometimes offering strawman comparisons, such as suggesting that individuals without markers of disease were healthy and from lack of understanding disease epidemiology (manifestations or lack thereof as population phenomena $[9,11]$. All "proofs" have been fatally methodologically flawed. Steckel, et al. [10] claimed health differences between the $19^{\text {th }}$ century Rochester poorhouse and middle class Belleville cemeteries, while Rothschild and Rothschild [12] documented that health was independent of economic status - no paradox. Sandberg, et al. [8] stated that "the 'osteological paradox' posits that the evaluation of health in archaeological populations is compli-

*Corresponding author: Bruce Rothschild, Carnegie Museum of Natural History, 4400 Forbes Ave, Pittsburgh, PA 15213, USA

Accepted: November 24, 2020

Published online: November 26, 2020

Citation: Rothschild B (2020) Paradoxical Support for the SoCalled "Osteological Paradox": An Attempt to Extirpate Evidence-Based Challenges to Speculation-Based Paradigms?. Insights Anthropol 4(2):303-305 
Citation: Rothschild B (2020) Paradoxical Support for the So-Called "Osteological Paradox": An Attempt to Extirpate Evidence-Based Challenges to Speculation-Based Paradigms?. Insights Anthropol 4(2):303-305

cated by three factors: Fluctuating demographic patterns, selective mortality, and variable susceptibility to illness among individuals." Fluctuating demographics suggested that skeletal samples do not represent the population from which they were drawn. That might be true if randomization were not observed and if burial of individuals occurred prior to when they would be expected to acquire and manifest a given disease. However, death itself was a random event, fulfilling the premise for statistical analysis. However, the major flaw in so-called proofs of the osteological paradox was choice of comparative populations. Sandberg, et al. [8] compared dental isotopes in contemporary 4-5 year-old individuals to isotopes in older individuals (referred to as survivors) from an archeologic site. Aside from failure to document that isotope findings are actually the same in two very disparate samples from a given individual, the authors failed to address bone replacement. The replacement rate of bone in ribs is at least $4 \%$ per year, even in older individuals [13], so what is being measured in an adult is not representative of what would have been found if they had been evaluated in childhood.

There has been a fundamental problem entailing persistence of use of falsified speculations as the basis for subsequent research and inadequate understanding of the premises for epidemiologic studies:

Wright and Yoder [4] considered attribution of porotic hyperostosis to iron deficiency, a subsequently debunked speculation $[14,15]$, as a mechanism to identify resistance to infections. This illustrated the major challenge of the osteological paradox. It was a strawman. It distracted attention from recognition that such speculation-based approaches were repeatedly promoted (e.g., [16]), despite their falsification $[15,17,18]$. Wright and Yoder [4] noted that malnourished contemporary children have a higher abundance of enamel hypoplasia, but then made the speculative converse claim that presence of hypoplasia in skeletal samples means the individuals suffered from malnutrition. Actually, enamel hypoplasia is a non-specific finding with many causes [19]. Wright and Yoder [4] further suggested that DNA studies would identify all individuals who had experienced specific diseases, mistakenly believing that such evidence would be uniformly retained. That again illustrated a misunderstanding of epidemiology. Sonnenschein and Soto [20] decry "the lack of significant improvements in the understanding of carcinogenesis." The consensus that has been achieved as to the elements "remained mostly irrelevant both to understanding carcinogenesis and to significantly benefiting the object of the whole effort, the cancer patient. There is a misunderstanding of the basic biological phenomenon.

Citing the "osteological paradox" has been used in attempts to denigrate any studies derived from skeletal populations $[4,8]$, despite notable rebuttals (e.g., [21]). That the individual (human or other animal) died was suggested as evidence that they were not representative of the population. Smith [22] mentioned "subsequent discussions" of the osteological paradox, but those she cited (i.e., [21,23-25]) found no evidence to support and which actually questioned that speculation. That speculation was clearly falsified by comparative studies of arthritis in wild caught and zoological park popula- tions $[26,27]$. Not only was the prevalence indistinguishable between the samples, but so, too, was the pattern of disease [27]. As long as the population samples had achieved the age by which the disease would have been acquired, they are comparable; thus, no paradox.

Snoddy, et al. [28] noted that "lack of awareness of best anthropological practices by scholars from other professional spheres can perpetuate a misunderstanding of the level of scientific study in our field," while failing to acknowledge the converse. Many in the field believed that scientific consensus identifies a group in which there is total agreement that a statement was valid. Actually, such a consensus was simply a group that agrees with and supports each other. It is not evidential. Snoddy, et al. [28] also noted that "palaeopathological methods have sometimes suffered from a kind of circular logic wherein older anthropological literature, which was no longer clinically accurate, was used as the foundation for entire diagnostic schemes." The osteological paradox was no exception. Repetition of a speculative comment was not evidence. It simply imbued a mythology. As Douglas Verret noted (12 September 2018, personal communication), consensus was political, not scientific.

Reporting of observations has seemingly been suggested (e.g., [29]), rather than scientific assessment of their implications. The rejoinder to such comments, illustrated in a geological perspective cited by Sonnenschein and Soto [20], is pertinent: "About 20 years ago there was much talk that geologists ought only to observe \& not theorise; \& I well remember someone saying that at this rate a man might as well go into a gravel-pit \& count the pebbles \& describe their coluours. How odd it is that everyone should not see that all observation must be for or against some view, if it is to be of any service." This was from an 18 September 1861 letter from Charles Darwin to Henry Fawcet [30].

If the osteological paradox speculation had merit, there would be little justification for study, other than to simply report observations - without any ability to interpret their significance. Fortunately, that speculation, unsubstantiated though oft repeated, does not have merit. Why does it persist? Perhaps it represents efforts to direct collective consciousness by denigration of scientifically test/vetted evidence that falsifies those speculations? If cemeteries and other skeletal collections were not representative of the population from which they are drawn, speculations would be untestable, those who depend upon ability to continue to espouse them could flourish.

As opposed to evidential approaches, consensus can be defined as the product of a group that agrees with and supports each other. Recall Douglas Verret's notation (12 September 2018, personal communication) that consensus is political, not scientific. Physicist Max Plank, quoted in the Times (UK) stated "a great scientific truth does not triumph by convincing its opponents and making them see the light, but rather because its opponents actually die" [31]. Physical anthropology, which studies the skeletons of organisms (both human and other) and often declines to offer itself for such study, has long been compromised by iteration of spec- 
Citation: Rothschild B (2020) Paradoxical Support for the So-Called "Osteological Paradox": An Attempt to Extirpate Evidence-Based Challenges to Speculation-Based Paradigms?. Insights Anthropol 4(2):303-305

ulations, often despite their falsification. What has been the "fruit" of past unsubstantiated speculations? Is it not time to move beyond those speculations to bask in the light of science?

\section{References}

1. Wood JW, Milner GR, Harpending HC, et al. (1992) The osteological paradox" problem of inferring prehistoric health from skeletal Samples [and Comments and Reply]. Curr Anthropl 33: 343-370.

2. Ortner D (1992) Skeletal pathology: Probabilities, possibilities, and impossibilities. In: Verano J, Ubelaker D, Disease and Demography in the Americas. Smithsoian Institution Press, Washington DC, 5-13.

3. McFadden C, Oxenham MF (2020) A paleoepidemiological approach to the osteological paradox: Investigating stress, frailty and resilience through cribra orbitalia. Am J Phys Anthropol 220: 1-13.

4. Wright LE, Yoder CJ (2003) Recent progress in bioarchaeology: Approaches to the osteological paradox. J Archaeol Res 11: 4370.

5. Kyle B, Reitsema L, Tyler J, et al. (2018) Examining the osteological paradox: Skeletal stress in mass graves versus civilians at the Greek colony of Himera (Sicily). Am J Phys Anthropol 167 161-172.

6. Buzon MR, Judd M (2008) Investigating health at Kerma: Sacrificial versus nonsacrificial individuals. American Journal of Physical Anthropology 136: 93-99.

7. Dewitte SD, Stojanowski CM (2015) The osteological paradox 20 years later: Past perspectives, future directions. J Archaeological Res 23: 397-450.

8. Sandberg P, Sponheimer M, Lee-Thorp J, et al. (2013) Addressing the osteologcal paradox using high resolution stable isotope analysis. Am J Phys Anthropol.

9. Siek T (2013) The osteological paradox and issues of interpretation in paleopathology. Explor Anthropol 12: 92-101.

10. Steckel RH, Rose JC, Larsen CS, et al. (2002) Skeletal health in the Western Hemisphere from $4000 \mathrm{BC}$ to the present. Evolutionary Anthropology 11: 142-155.

11. Goodman AH (1993) On the interpretation of health from skeletal remains. Curr Anthropol 34: 281-288.

12. Rothschild BM, Rothschild C (1993) $19^{\text {th }}$ spondyloarthropathy independent of socioeconomic status: Lack of skeletal collection bias. J Rheumatol 20: 314-319.

13. Fahy GE, Deter C, Pitfield R, et al. (2017) Bone deep: Variation in stable isotope ratios and histomorphometric measurements of bone remodelling within adult humans. J Archaeol Sci 87: 10-16.
14. Walker PL, Bathurst RR, Richman R, et al. (2009) The causes of porotic hyperostosis and cribra orbitalia: A reappraisal of the iron-deficiency-anemia hypothesis. Am J Phys Anthropol 39: 109-125.

15. Rothschild BM (2012) Extirpolation of the mythology that porotic hyperostosis is caused by iron deficiency secondary to dietary shift to maize. Adv Anthropol 2: 157-160.

16. Brickley MB (2018) Cribra orbitalia and porotic hyperostosis: A biological approach to diagnosis. Am J Phys Anthropol 167: 896902.

17. Rivera F, Mirazón Lahr M (2017) New evidence suggesting a dissociated etiology for cribra orbitalia and porotic hyperostosis. Am J Phys Anthropol 164: 76-96.

18. Rothschild BM, Ruhli FJ, Sebes J, et al. (2005) Relationship between porotic hyperostosis and cribra orbitalia? Paleobios 13: 4-7.

19. Nikiforuk G, Fraser D (1981) The etiology of enamel hypoplasia: A unifying concept. J Pediatr 98: 888-893.

20. Sonnenschein C, Soto AM (2020) Over a century of cancer research: Inconvenient truths and promising leads. PLoS Biol 18: e3000670.

21. Cohen MN, Wood JW, Milner GR (1994) The osteological paradox reconsidered. Curr Anthropol 35: 629-637.

22. Smith MO (2013) Paleopathology. In: DiGangi EA, Moore MK, Research Methods in Human Skeletal Biology. Elsevier, 181-217.

23. Byers S (1994) On stress and stature in the "osteological paradox". Curr Anthropol 35: 282-284.

24. Jackes M (1993) On paradox and osteology. Curr Anthropol 34: 434-439.

25. Mendonça de Souza SM, de Carvalho DM, Lessa A (2003) Paleoepidemiology: Is there a case to answer? Mem Inst Oswaldo Cruz 98: 21-27.

26. Rothschild BM, Martin LD (2006) Skeletal impact of disease. New Mexico Museum of Natural History Press, Albuquerque.

27. Rothschild BM, Woods RJ (1989) Spondyloarthropathy in gorillas. Semin Arthritis Rheum 18: 267-276.

28. Snoddy AM, Beumont J, Buckley HR, et al. (2020) Sensationalism and speaking to the public: Scientific rigour and interdisciplinary collaborations in paleopathology. Intl J Paleopath 28: 81-91.

29. Smith RJ (2019) Living with observational data in biological anthropology. Am J Phys Anthropol 169: 591-598.

30. Burkardt Frederick, Sydney Smith (1985) The correspondence of Charles Darwin. Cambridge University Press, Cambridge.

31. Anonymous (2019) Wit \& wisdom. The Week 20: 23.

DOI: $10.36959 / 763 / 516$

Copyright: (C) 2020 Rothschild B. This is an open-access article distributed under the terms of the Creative Commons Attribution License, which permits unrestricted use, distribution, and reproduction in any medium, provided the original author and source are credited. 